\title{
Effects of spoilage on nitrogen and carbon stable isotopes signatures of the clam Ruditapes decussatus
}

\author{
Jaime Aníbal ${ }^{1,2 *[0000-0002-9704-5824]}$, Cristina Veiga-Pires ${ }^{1,3[0000-0002-9323-0723]}$ and Eduardo \\ Esteves $^{2,4[0000-0002-1872-8185]}$ \\ ${ }^{1}$ CIMA - Centro de Investigação Marinha e Ambiental, Universidade do Algarve, Campus de \\ Gambelas, 8005-139 Faro, Portugal \\ janibaleualg.pt \\ ${ }^{2}$ Instituto Superior de Engenharia, Universidade do Algarve, Campus da Penha, 8005-139 Faro, \\ Portugal \\ ${ }^{3}$ Faculdade de Ciências e Tecnologia, Universidade do Algarve, Campus de Gambelas, 8005- \\ 139 Faro, Portugal \\ cvpires@ualg.pt \\ ${ }^{4}$ CCMAR - Centro de Ciências do Mar, Campus de Gambelas, 8005-139 Faro, Portugal \\ eesteves@ualg.pt
}

\begin{abstract}
Fish and seafood products are highly susceptible to post-mortem spoilage due to autolytic reactions at start, then microbiological activity and eventually oxidative reactions. Chemical and microbiological parameters are usually used to assess quality and make decisions for protecting public health, but they lack precision in defining which spoilage pathway is occurring at each moment. The objective of this work was to assess the effects of spoilage reactions on nitrogen and carbon stable isotopes in the grooved carpet shell clam, Ruditapes decussatus, and compare them to biochemical indicators of seafood deterioration, in order to better understand the relations between the different spoilage pathways during commercial storage conditions. Clams were kept in a refrigerator at $5{ }^{\circ} \mathrm{C}$, to simulate normal commercial storage conditions, and sampled in the beginning of the experiment, and after eight, ten and twelve days. Moisture, condition index, percentage edibility, total volatile basic nitrogen (TVB-N), $\mathrm{pH}$, nitrogen and carbon percentages and stable isotopes were determined for each sampling moment. Stable isotope analyses were performed using a Costech Elemental Analyzer (ECS 4010) coupled to a ThermoFinnigan Delta V Advantage. Stable isotopes analysis, especially for nitrogen, proved to be a good tool for the study of clam deterioration. Nitrogen stable isotopes results showed a relation with other spoilage indicators, such as $\mathrm{pH}$ and TVB-N, and allowed identifying spoilage specific pathways, such as amino acids decarboxylation and production of volatile nitrogen compounds.
\end{abstract}

Keywords: Stable isotopes, Carbon, Nitrogen, Spoilage, TVB-N 


\section{Introduction}

From a nutritional point of view, seafood in general, and bivalves in particular, are normally consumed for their high content in proteins and unsaturated fatty acids. Those same groups of molecules are also the cause for rapid deterioration, leading to serious food safety issues. The condition named "spoilage" is not clearly defined in objective terms, but it is related with post-mortem conditions. Seafood spoilage is the set of sensory changes, resulting from the production of off-odors, off-flavors, slime, gas, discoloration and changes in texture. These signs result in products being unacceptable for human consumption, and are caused by three groups of phenomena, that act almost sequentially: initially there are the autolytic chemical changes; followed by the bacterial metabolism, where spoilage occurs actively; and lastly lipids are chemically oxidized [1]. The rate and relative importance of each group of phenomena depends on the group of food species being studied (e.g. lean or fat fishes, crustaceans, bivalves).

Besides the current practice of evaluating seafood freshness based on sensory attributes in the commercial and industry sectors, seafood spoilage is assessed through chemical (e.g. nitrogen- or biogenic amines-based indices) and microbiological counts (e.g. TVC, Escherichia coli, Listeria monocytogenes). Although these indicators support public health decisions regarding the consumption of seafood, they usually lack precision in defining biochemical pathways underpinning spoilage. For instance, chemical indicators of spoilage can originate from autolytic processes or as a consequence of microbiota metabolism; the presence of microbiota does not always means that spoilage is occurring. Herein, we study the opportunity of using stable isotopes of relevant chemical elements, nitrogen and carbon, that are involved in the deterioration reactions, in order to identify which phenomena or biochemical pathways are temporarily controlling the seafood spoilage.

Stable isotopes are traditionally used in geochemistry to assess the chemical processes controlling the lithosphere, hydrosphere and atmosphere [9], and in ecology and environmental sciences to trace the flow of organic matter in food webs $[18,24]$. More recent approaches use stable isotope analysis in archaeology to assess human dietary preferences in the past $[8,12]$ and in food sciences to determine food products authentication [7], traceability [22] and geographic origin [15]. To our knowledge, stable isotopes have not been used before to study seafood spoilage.

The use of nitrogen and carbon stable isotopes relies on their ubiquitous presence in organic matter and thus in the edible part of food, as in clam's meat. Stable isotopes analysis is based on the ratio of abundance of heavy isotope to the light isotope of a single element, namely $\mathrm{N}$ or $\mathrm{C}$ in the present work. This ratio changes during chemical and/or biological processes because the atomic mass of different isotopes affects the chemical kinetics of reactions involving the element of choice, leading natural isotope fractionation. Characterizing the direction and extent of such fractionation allows insights into the processes that are occurring in a defined environment [3].

Carbon isotopes are usually studied to differentiate among sources of organic matter and to clarify food webs carbon flow pathways, whereas nitrogen isotopes 
provide information on trophic level as well as on organic matter origin [20, 23]. In fact, both carbon and nitrogen isotopes are dependent on kinetic effects, which are irreversible and predominantly due to biological processes/mechanisms, such as respiration, and equilibrium effects between different matter phases, such as evaporation. This is why their analysis for spoilage evaluation could be of interest, besides the fact that only a very small quantity of sample is needed for such analysis.

The grooved carpet shell clam, Ruditapes decussatus (L. 1758), is one of the most popular and profitable mollusks exploited in rearing plots in the Mediterranean, and adjacent coastal areas, being used as a food source for centuries [2].

The objective of this study was to examine the effects of spoilage-related dynamics of nitrogen and carbon stable isotopes in $R$. decussatus, and compare them to biochemical indicators, in order to better understand the relations between the different aspects promoting seafood spoilage during commercial storage conditions.

\section{$2 \quad$ Materials and methods}

\subsection{Sampling and processing}

Grooved carpet shell clams ( $R$. decussatus) of commercial value ( $\mathrm{n}=140$ individuals) were obtained directly from a production plot located in the Ria Formosa (tidal lagoon in the South of Portugal). Immediately after harvest, the clams were transported to the laboratory in a refrigerated box and our experiment started with the clams' being stored at $5{ }^{\circ} \mathrm{C}$, simulating the typical storage conditions during commercialization. Clams were sampled in the beginning of the experiment (d0), and subsequently after eight (d8), 10 (d10) and 12 days (d12). In each sampling moment, 34 specimens were randomly selected, four of which were used individually to measure stable isotopes abundances, percentage edibility and condition index. The remaining clams were used to determine total volatile basic nitrogen (TVB-N), $\mathrm{pH}$ and moisture. The latter were determined in three replicates obtained by dividing the 30 clams into three groups composed by a pool of soft tissue from ten clams. These analyses were always performed at the same time of the day ( 9 a.m.). On each sampling occasion, the responsiveness to mechanical stimulation of the mantle, done using a metal stiletto, was observed and classified as: "alive" if a reaction was observed; or "dead" if no response was observed.

\subsection{Chemical analysis}

TVB-N was determined according to the Conway method [5], and expressed as milli-

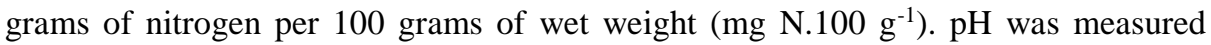
directly on clam's muscle tissues using a digital meter (model Glp 21, Crison, Spain). Moisture content of the meat was calculated using the [4] method ref 950.46 . 


\subsection{Condition index and percentage edibility}

Biological condition of specimens was assessed using the percentage edibility (PE) and condition index (CI) calculated as

$$
\mathrm{PE}=(\mathrm{MWW} / \mathrm{TW}) \times 100
$$

where MWW is meat wet weight (g) and TW is the total clam weight including the shell $(\mathrm{g})[19,27]$ and

$$
\mathrm{CI}=(\mathrm{MDW} / \mathrm{SDW}) \times 1000
$$

where MDW is meat dry weight $(\mathrm{g})$ and SDW is the shell dry weight $(\mathrm{g})[14,21]$.

\subsection{Stable isotope analysis}

Individual clams from a similar age group (about $25 \mathrm{~mm}$ maximum shell length) were weighted $( \pm 0.1 \mathrm{mg})$. Samples were manually shucked by cutting the adductor muscle with a knife, and all the soft tissues were weighted. Contamination between samples was prevented by treating all specimens separately and by cleaning the cutting board and dissection tools between samples. The samples were subsequently dried at $60{ }^{\circ} \mathrm{C}$ for $48 \mathrm{~h}$ and weighted again. The desiccated soft tissues were ground to a homogenous fine powder using mortar and pestle, and stored in aluminum foil pouches. Grinding tools were decontaminated between samples using hydrogen peroxide $(30 \%)$, hydrochloric acid (10\%) and de-ionized water (MilliQ cartridge). Stable isotope analyses were performed using a Costech Elemental Analyzer (ECS 4010) coupled to a ThermoFinnigan Delta V Advantage. The isotopic composition $\delta^{15} \mathrm{~N}$ is expressed in per mil (\%) relative to the atmospheric nitrogen standards (N2 atm) [6]. The isotopic composition $\delta^{13} \mathrm{C}$ is also expressed in per mil (\%o) relative to Belemnitella Americana from the Cretaceous Peedee formation, South Carolina (V-PDB) [6]. Stable isotopes are reported in delta $(\delta)$ notation according to

$$
\delta^{\mathrm{n}} \mathrm{X}=\left(\left[R_{\text {sample }} / R_{\text {standard }}\right]-1\right) \times 10^{3}
$$

where $\mathrm{X}=\mathrm{N}$ or $\mathrm{C} ; \mathrm{n}=$ atomic mass of heaviest isotope; $R={ }^{15} \mathrm{~N}:{ }^{14} \mathrm{~N}$ or $R={ }^{13} \mathrm{C}:{ }^{12} \mathrm{C}$. Data accuracy was monitored through routine analyses of in-house standards, which are calibrated against international standards. Nitrogen and carbon content was also assessed in the dried samples.

\subsection{Statistics}

Initially, linear discriminant analysis (LDA) of individually determined parameters (CI, PE, carbon content, $\delta^{13} \mathrm{C}$, nitrogen content, $\delta^{15} \mathrm{~N}$ and $\mathrm{C} / \mathrm{N}$ ratio) was carried out to account for the variation in isotopic composition due to the time of death differing from the actual sampling instant. Two specimens were 'reclassified' into different sampling days according to the 'best' LDA model (Accuracy $=0.875$, No Information Ratio $(\mathrm{NIR})=0.25$ with $\mathrm{p}=2.6 \times 10^{-7}$ ) that included variables $\mathrm{PE}, \delta^{15} \mathrm{~N}$ and CI. The 're- 
classified' data were used thereafter. One-way analysis of variance (ANOVA) and the Tukey HSD test for post-hoc multiple comparisons were carried out to uncover any significant changes over time on the magnitude of spoilage indicators. Whenever the homogeneity of variances could not be verified (via Levene's test), Welch's F-test was used instead of ANOVA and multiple comparisons were done using the GamesHowell test. All analyses were conducted using R [26] and a level of significance of 0.10 was chosen has a reasonable balance between type I and type II errors, considering individual variation and the amount of data.

\section{$3 \quad$ Results}

During the experiment, all clams were responsive to mechanical stimulation during the first seven days, and thus considered to be alive. Between d7 and d10, clams progressively stopped responding to stimuli. After d10, all remaining clams were considered dead because they were unresponsive to mechanical stimulation, and their shells were permanently closed due to rigor mortis. In the last day of the experiment (d12), some clams opened their valves again displaying signs of post-rigor.

Change of spoilage and quality-related parameters in clams as a result of sampling time is presented in Figure 1 and the results of statistical analyses summarized in Table 1. Moisture content showed a slight but significant $(\mathrm{p}=0.028)$ decrease $(81.4 \%$ to $79.6 \%$ ) with time. In contrast, TVB-N values were practically constant (ca. $8 \mathrm{mg} \mathrm{N} / 100 \mathrm{~g}$ ) while clams were alive, and increased rapidly (and significantly; $\mathrm{p}=0.032$ ) after death (to $20.8 \mathrm{mg} \mathrm{N} / 100 \mathrm{~g}$ at $\mathrm{d} 12$ ). An increasing and significant $(\mathrm{p}<0.001)$ trend was also observed for $\mathrm{pH}(6.3$ to 7.7$)$. On the other hand, the condition index decreased over time in opposition to the percentage edibility even if differences between $\mathrm{d} 0$ and $\mathrm{d} 12$ were non-significant for both.

In terms of stable isotopes, nitrogen content and $\delta^{15} \mathrm{~N}$ signature have similar trends, decreasing from $\mathrm{d} 0$ to $\mathrm{d} 8$, increasing between $\mathrm{d} 8$ and $\mathrm{d} 10$, and decreasing afterwards. Conversely, carbon content and $\delta^{13} \mathrm{C}$ signature did not vary in a significant way (ANOVA, $p>0.10$ ) during the experiment. The carbon-nitrogen ratio offsets the trends observed for nitrogen and varied significantly (ANOVA, $\mathrm{p}=0.027$ ) among sampling days (Table 1 and Figure 2).

The relationships among $\delta^{15} \mathrm{~N}$ and $\delta^{13} \mathrm{C}$ and their respective elemental concentrations are illustrated in Figure 3. Both $\mathrm{C}$ and $\mathrm{N}$ isotopic signatures vary slightly from heavier towards lighter compositions, except for d10, which shows the most ${ }^{15} \mathrm{~N}$ enriched value together with the higher $\mathrm{C}$ and $\mathrm{N}$ contents. 

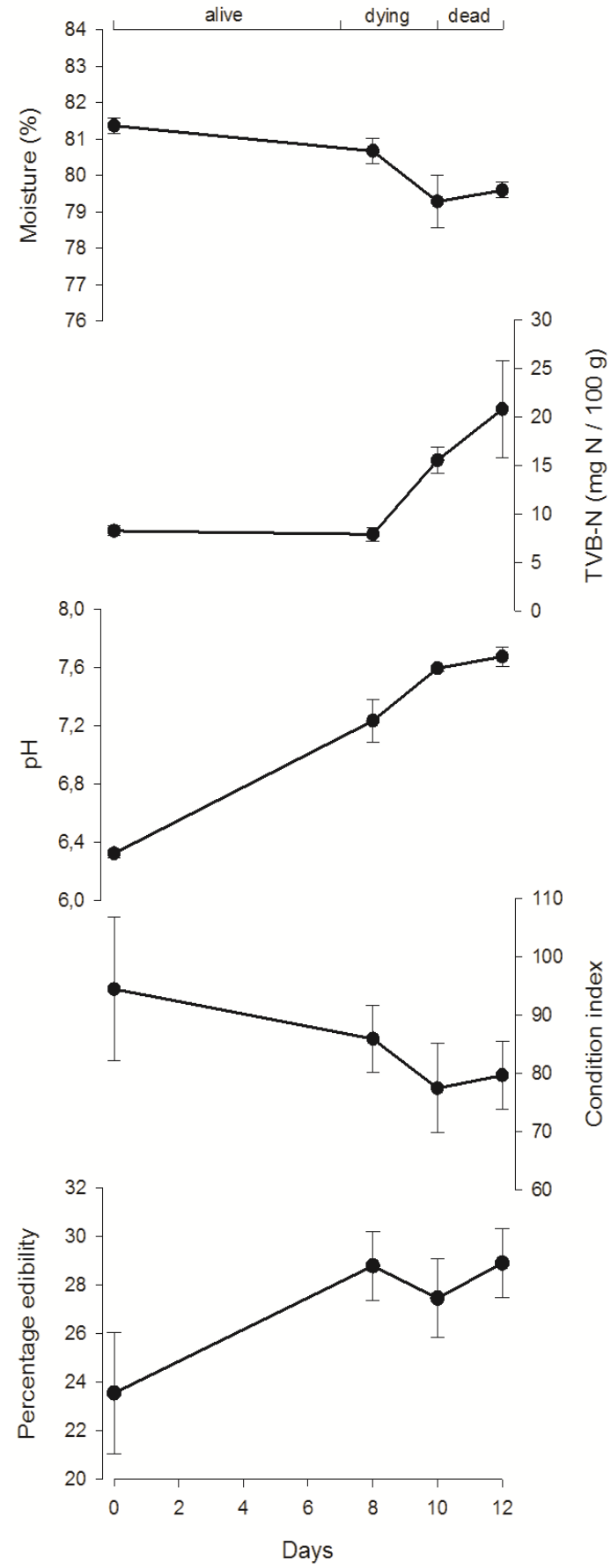

Fig. 1. Temporal variations (mean \pm standard error) of moisture, TVB-N, $\mathrm{pH}$, condition index and percentage edibility in $R$. decussatus during chilled storage. 
Table 1. Results of one-way ANOVA and multiple comparisons post-hoc tests applied to the parameters analyzed during chilled storage of clams $R$. decussatus.

\begin{tabular}{|c|c|c|c|}
\hline Parameter & Mean $^{\S}$ & $\mathbf{F}$ & $p$ \\
\hline Moisture (\%) & & 5.20 & 0.028 \\
\hline Time (days) 0 & $81.4^{\mathrm{b}}$ & & \\
\hline 8 & $80.7^{\mathrm{ab}}$ & & \\
\hline 10 & $79.3^{\mathrm{a}}$ & & \\
\hline 12 & $79.6^{\mathrm{a}}$ & & \\
\hline TVB-N (mg N/100 g) & & $8.56^{\mathbb{I}}$ & 0.032 \\
\hline Time (days) 0 & $8.2^{\mathrm{a}}$ & & \\
\hline 8 & $7.9^{\mathrm{b}}$ & & \\
\hline 10 & $15.5^{\mathrm{ab}}$ & & \\
\hline 12 & $20.8^{\mathrm{b}}$ & & \\
\hline $\mathrm{pH}$ & & $362.34^{\text {II }}$ & $<0.001$ \\
\hline Time (days) 0 & $6.3^{\mathrm{a}}$ & & \\
\hline 8 & $7.2^{\mathrm{b}}$ & & \\
\hline 10 & $7.6^{\mathrm{c}}$ & & \\
\hline 12 & $7.7^{\mathrm{c}}$ & & \\
\hline Condition Index ${ }^{\mathscr{H}}$ & 85.1 & 1.09 & 0.393 \\
\hline Edibility $(\%)^{\mathscr{H}}$ & 27.4 & 2.11 & 0.153 \\
\hline Carbon $(\%)^{\mathscr{H}}$ & 41.1 & 0.48 & 0.703 \\
\hline Nitrogen $(\%)^{\mathscr{H}}$ & & 6.42 & 0.008 \\
\hline Time (days) 0 & $10.63^{\mathrm{bc}}$ & & \\
\hline 8 & $10.24^{\mathrm{a}}$ & & \\
\hline 10 & $10.93^{\mathrm{c}}$ & & \\
\hline 12 & $10.34^{\mathrm{ab}}$ & & \\
\hline $\mathrm{C} / \mathrm{N}$ ratio $^{\mathscr{H}}$ & & 3.75 & 0.042 \\
\hline Time (days) 0 & $4.52^{\mathrm{ab}}$ & & \\
\hline 8 & $4.68^{\mathrm{b}}$ & & \\
\hline 10 & $4.43^{\mathrm{a}}$ & & \\
\hline 12 & $4.60^{\mathrm{ab}}$ & & \\
\hline$\delta^{13} \mathrm{C}(\%)^{\mathscr{H}}$ & -18.12 & 2.03 & 0.163 \\
\hline$\delta^{15} \mathrm{~N}(\% 0)^{\mathscr{H}}$ & & 4.34 & 0.027 \\
\hline Time (days) 0 & $8.66^{\mathrm{b}}$ & & \\
\hline (1) & $8.18^{\mathrm{ab}}$ & & \\
\hline 10 & $8.78^{\mathrm{b}}$ & & \\
\hline 12 & $8.14^{\mathrm{a}}$ & & \\
\hline
\end{tabular}

Legend: $\S$ - In case of significant ANOVA results (where $p<0.10$ ), means per sampling time (days) are presented - values sharing a common superscript are not significant at $\alpha=0.10$ (Tukey HSD test); ${ }^{\mathscr{H}}$ - Data considering the "re-classified" individuals according to LDA (see main text for further details); ${ }^{\mathbb{T}}$ - Due to lack of homogeneity among variances (Levene's test $\mathrm{p}<0.05$ ), the Welch's adjusted F-ratio and the Games-Howell post-hoc test were used instead of ANOVA and Tukey HSD, respectively. 

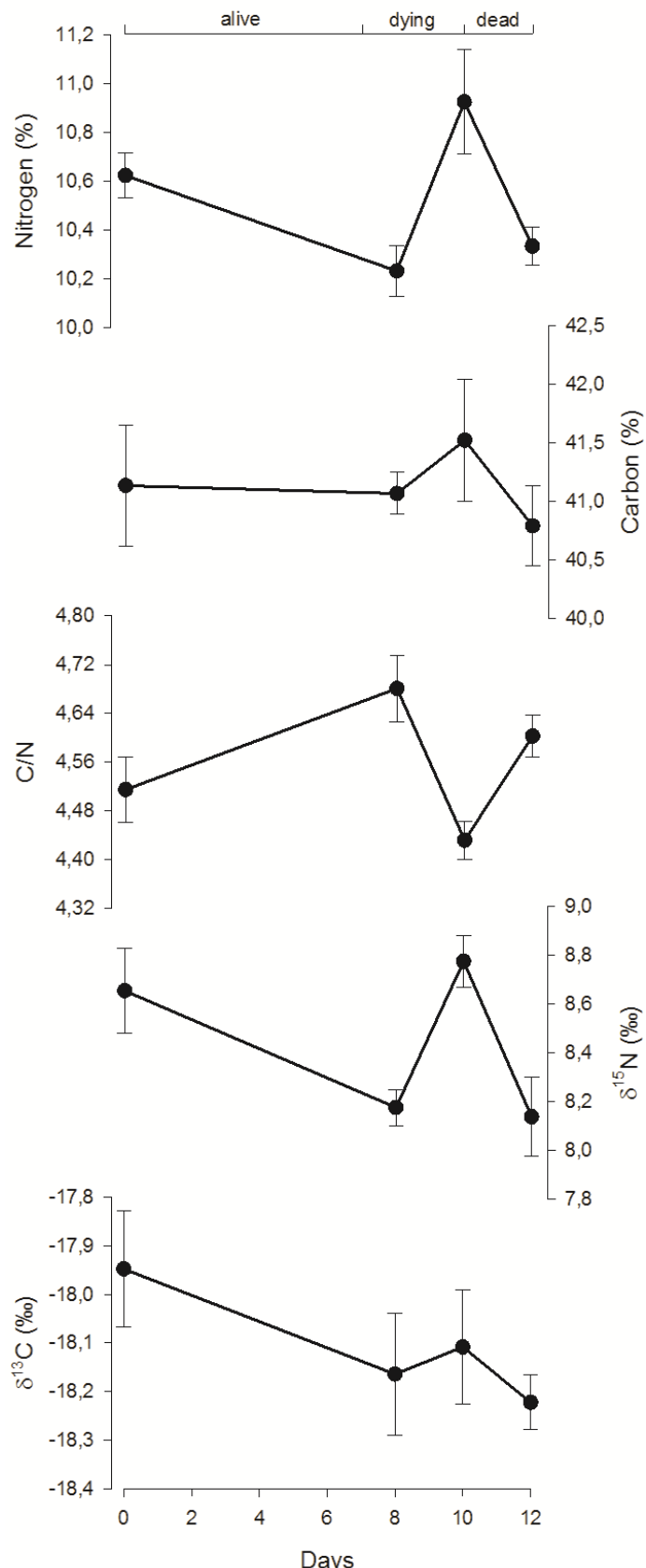

Fig. 2. Temporal variations (mean \pm standard error) of nitrogen and carbon contents, carbonnitrogen ratio, and $\delta^{15} \mathrm{~N}$ and $\delta^{13} \mathrm{C}$ abundances in $R$. decussatus during chilled storage. 

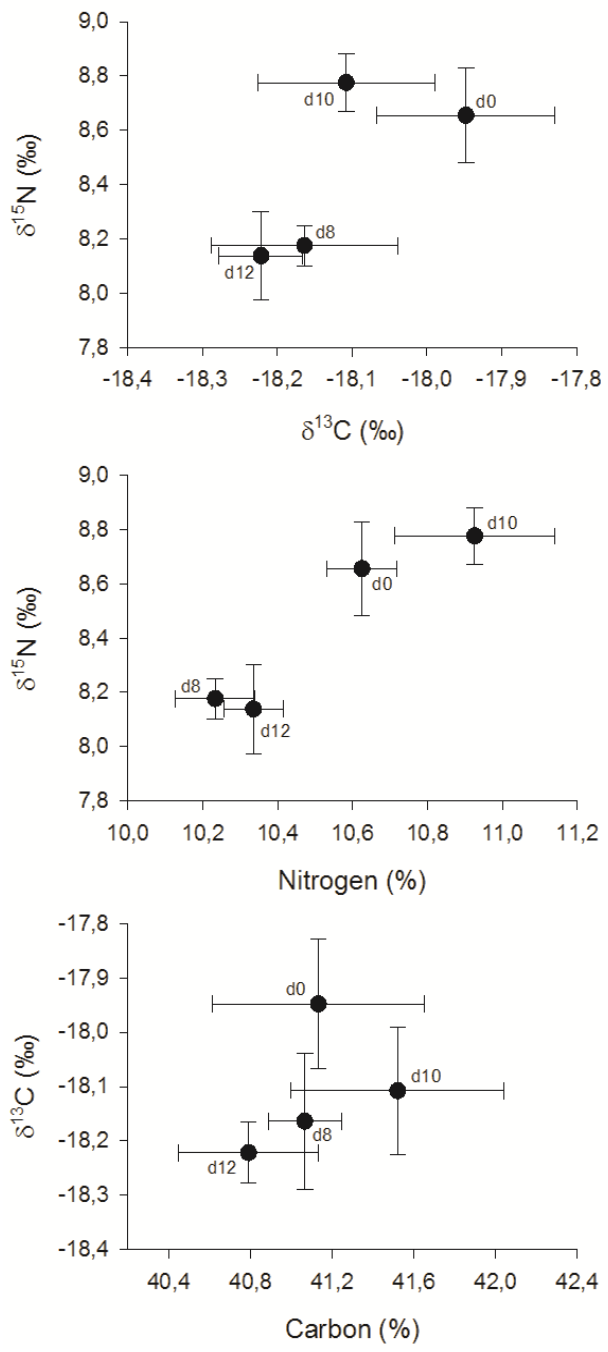

Fig. 3. Relations between of $\delta^{15} \mathrm{~N}$ and $\delta^{13} \mathrm{C}$ contents, and between each stable isotope composition and its respective elemental content.

\section{Discussion}

In each sampling moment, the majority of analyzed parameters showed a significant variation among their replicates values, especially in the elemental and stable isotopic parameters. This observation can probably be explained by individual specific characteristics and the fact that the clams died at different days (between $\mathrm{d} 7$ and d10), making the standard error higher because the sampled clams, although having the same 
time of experiment, had different times of death, which interfere with the level of spoilage, because spoilage only truly starts after the individuals death [11].

The continuous increase in $\mathrm{pH}$ shows that muscle alterations began once the individuals were captured and subject to food deprivation, even when they were still alive. Post-mortem $\mathrm{pH}$ increase indicates lack of important lactic acid production. The main spoilage processes in action here must therefore be related to the production of basic compounds resulting from nitrogen deamination, as shown by the increase in TVB-N.

Our results compare well with those of Aníbal et al. [2] for PE and CI, indicating a consistent annual cycle in the physiological conditions of this species. PE is not a good spoilage index for experiments conducted in a refrigerated chamber because once the individuals open their valves the intravalvar water is loss, which can be misleading, given that loss of water might then suggest, through PE, that during spoilage clams increase their edible content. Instead, CI is a good index for clam deterioration because it is related to dry weight and hence not influenced by moisture content.

Regarding the carbon and nitrogen stable isotope signatures, the values obtained for the clams at the beginning of the experiment are in agreement with previously published data from the same species and same environment [16]. The initial decrease of nitrogen content (from d0 to $\mathrm{d} 8$ ) may be a response to metabolic starvation, where muscle tissue is catabolized to produce energy, with ammonia formation and subsequent elimination. This is supported by lower $\delta^{15} \mathrm{~N}$ values associated with a loss in the heavy ${ }^{15} \mathrm{~N}$ isotope [17]. After the animals' death, the microbiota that developed in the in-shell liquid start colonizing the meat, increasing the total nitrogen content because they are also sampled and quantified along with the clam's flesh. The observed enrichment in heavy isotopes from $\mathrm{d} 8$ to $\mathrm{d} 10$ is also reflecting the addition of microorganisms that were developing onto the heavier excreted in-shell fluids with a probable $\mathrm{N}$ concentration effect explaining different enrichment factors compared initial isotopic signatures $[10,25]$. From this moment on (d10 to d12), equilibrium is established between the microbiota proliferation and the nitrogen losses by the formation of volatile compounds attested by TVB-N content. This process is registered in the decrease of $\delta^{15} \mathrm{~N}$ values and can be linked either to the continuation of progressive deamination [17] or to bacterial growth adding ${ }^{15} \mathrm{~N}$-depleted biomass to the deteriorating clam flesh [13].

Carbon content did not show significant variations during the experiment because spoilage processes in clams/seafood are normally nitrogen related (Huss et al. 2004). However, the $\mathrm{C}$ isotopic compositions does reflect a ${ }^{13} \mathrm{C}$-depletion from $\mathrm{d} 0$ to $\mathrm{d} 8$, while clams are dying and living on their own resources, probably reflecting a selective preservation of ${ }^{13} \mathrm{C}$-depleted organic compounds and release of ${ }^{13} \mathrm{C}$ enriched $\mathrm{CO}_{2}$ [13]. Between $\mathrm{d} 8$ and $\mathrm{d} 10$, the observed increase in $\delta^{13} \mathrm{C}$ values may be due to the incorporation of bacterial cells enriched in ${ }^{13} \mathrm{C}$ relative to clam flesh, also explaining the decrease in $\mathrm{C} / \mathrm{N}$, or to equilibrium isotopic effects within the shell inducing a preferential loss of light carbon [17]. Finally, d10 to d12 present a decrease in $\delta^{13} \mathrm{C}$, probably linked again to a ${ }^{13} \mathrm{C}$ preferential release but this time due to bacterial feeding onto the degraded clam organic matter, as observed in oxic algal degradation [13]. 
In order to fully understand the results it is necessary to comprehend that while the clams were alive, bacteria only survived and feed in the intravalvar liquid, not being accounted in the stable isotopes analysis. Once the clams died, bacteria colonized the clam flesh and their isotopic composition merged with the clams' flesh itself, making the results' interpretation more complex.

\section{Conclusions}

Stable isotopes analysis, especially for nitrogen, proved to be a good tool for the study of clam deterioration and its underpinning drivers. $\delta^{15} \mathrm{~N}$ results were able to be related with other spoilage indicators, such as $\mathrm{pH}$ and TVB-N, and were also suitable to identify spoilage specific reactions, such as the decarboxylation of amino acids and production of volatile nitrogen compounds.

In future studies, $\delta^{34} \mathrm{~S}$ might prove to be a good spoilage related parameter, because of the action of hydrogen sulfide-producing bacteria, which are considered spoilage specific organisms.

Regarding spoilage assessment, stable isotopes analysis is possibly not a good method for immediate quality control assessment, because it is not a rapid method, and requires very expensive instruments that are very difficult to master technically. But stable isotopes analysis might play a future role in setting-up or verifying quality assurance programs, where rapidity and cost are less important.

\section{Acknowledgements.}

The research leading to these results was primarily funded by the project NITROLINKS - NITROgen loading into the Ria Formosa through Coastal Groundwater Discharge (CGD) - Pathways, turnover and LINKS between land and sea in the Coastal Zone (PTDC/MAR/70247/2006) funded by the Portuguese Foundation for Science and Technology (FCT). This work was also supported by the Portuguese Science Foundation (FCT) through the grant UID/MAR/00350/2013 attributed to CIMA of the University of Algarve, and through project UID/Multi/04326/2013 attributed to CCMAR. We would also like to thank Dr. Carlos Rocha for his contribution to the stable isotopes analysis and for his insights regarding the discussion of the results.

\section{References}

1. Alasalvar, C., Shahidi, F., Miyashita, K., Wanasundara, U.: Handbook of seafood quality, safety and health application. West Sussex, UK, Wiley-Blackwell (2011).

2. Aníbal, J., Esteves, E. Rocha, C.: Seasonal variations in gross biochemical composition, percentage edibility, and condition index of the clam Ruditapes decussatus cultivated in the Ria Formosa (South Portugal). J. Shellfish Res. 30, 17-23 (2011).

3. Aníbal, J., Veiga-Pires, C.: Trace elements and stable isotopes analysis as seafood quality indicators. In: Genç, I. Y.; Esteves, E., \& Diler, A. (eds.) Handbook of Seafood: Quality 
and Safety Maintenance and Applications, Chapter 8, pp. 139-149. Nova Science Publishers, Inc, New York (2016).

4. AOAC: Official methods of analysis. $18^{\text {th }}$ edition, Maryland, USA, Association of Official Analytical Chemists (2005).

5. Conway, E.J., Byrne, A.: An absorption apparatus for the micro - determination of certain volatile substances. I. The micro - determination of ammonia. Biochem. J. 27, 419-429 (1933).

6. Coplen, T.B.: Guidelines and recommended terms for expression of stable- isotope-ratio and gas-ratio measurement results. Rapid Commun. Mass Spectrom. 25, 2538-2560 (2011).

7. Ghidini, S., Ianieri, A., Zanardi, E., Conter, M., Boschetti, T., Iacumin, P., Bracchi, P.G.: Stable isotopes determination in food authentication: a review. Ann. Fac. Medic. Vet. Di Parma 26, 193-204 (2006).

8. Hedges, R.E.M., Reynard, L.M.: Nitrogen isotopes and the trophic level of humans in archaeology. J. Archaeol. Sci. 34, 1240-1251 (2007).

9. Hoefs, J.: Stable isotope geochemistry. Springer-Verlag Berlin Heidelberg (2009).

10. Hondula, K., Pace, M.: Macroalgal support of cultured hard clams in a low nitrogen coastal lagoon. Mar. Ecol. Prog. Ser. 498, 187-201 (2014).

11. Huss, H.H.; Ababouch, L., Gram, L.: Assessment and management of seafood safety and quality. FAO Fisheries Technical Paper 444 (2004).

12. Kosiba, S.B., Tykot, R.H., Carlsson, D.: Stable isotopes as indicators of change in food procurement and food preference of Viking Age and Early Christian populations on Gotland (Sweeden). J. Anthropol. Archaeol. 26, 394-441 (2007).

13. Lehmann, M.F., Bernasconi, S.M., Barbieri, A., Mckenzie, J.A.: Preservation of organic matter and alteration of its carbon and nitrogen isotope composition during simulated and in situ early sedimentary diagenesis. Geochim. Cosmochim. Acta 66, 3573-3584 (2002).

14. Lucas, A., Beninger, P.G.: The use of physiological condition indices in marine bivalve aquaculture. Aquaculture 44, 187-200 (1985).

15. Luykx, D.M.A.M., van Ruth, S.M.: An overview of analytical methods for determining the geographical origin of food products. Food Chem. 107, 897-911 (2008).

16. Machás, R., Santos, R., Peterson, B.: Tracing the flow of organic matter from primary producers to filter feeders in Ria Formosa lagoon, Southern Portugal. Estuaries 26, 846-856 (2003).

17. Macko, S.A., Estep, M.L.F.: Microbial alteration of stable nitrogen and carbon isotopic compositions of organic matter. Org. Geochem. 6, 787-790 (1984).

18. Michener, R., Lajtha, K.: Stable isotopes in ecology and environmental science. Malden, MA: Blackwell Publishing Ltd. (2007).

19. Mohite, S.A., Mohite, A.S., Singh, H.: On condition index and percentage edibility of the shortneck clam Paphia malabarica (Chemintz) from estuarine regions of Ratnagiri, west coast of India. Aquacult. Res. 40, 69-73 (2009).

20. Newton, J.: Stable Isotope Ecology. Encycl. Life Sci., 1-7 (2010).

21. Orban, E., Di Lena, G., Nevigato, T., Casini, I., Caproni, R., Santorini, G., Giulini, G.: Nutritional and commercial quality of the striped venus clam, Chamelea gallina, from the Adriatic sea. Food Chem. 101, 1063-1070 (2006).

22. Peres, B., Barlet, N., Loiseau, G., Montet, D.: Review of the current methods of analytical traceability allowing determination of the origin of foodstuffs. Food Control 18, 228-235 (2007).

23. Petersen, B.J.: Stable isotopes as tracers of organic matter of organic matter input and transfer in benthic food webs: a review. Acta Oecol. 20, 479-487 (1999). 
24. Petersen, B.J., Fry, B.: Stable isotopes in ecosystem studies. Annu. Rev. Ecol. Syst. 18, 293-320 (1987).

25. Philips, D.L., Koch, P.L.: Incorporating concentration dependence in stable isotope mixing models. Oecol. 130, 114-125 (2002).

26. R Core Team: R: A language and environment for statistical computing. R Foundation for Statistical Computing, Vienna, Austria. ISBN 3-900051-07-0, http://www.R-project.org (2014).

27. Venkataraman, R., Chari, S.D.T.: Studies on oysters and clams - biochemical variations. Indian J. Med. Res. 39, 533-541 (1951). 